\title{
ANÁLISIS MULTIMODAL A UNA FOTOGRAFía DE ABDÚ ELJAIEK
}

\section{MULTIMODAL ANALYSIS OF A ABDÚ ELJAIEK'S PHOTOGRAPHY}

\section{ANÁlise MULTimodAl DE UMA FOTOGRAFIA DE ABDÚ ELJAIEK}

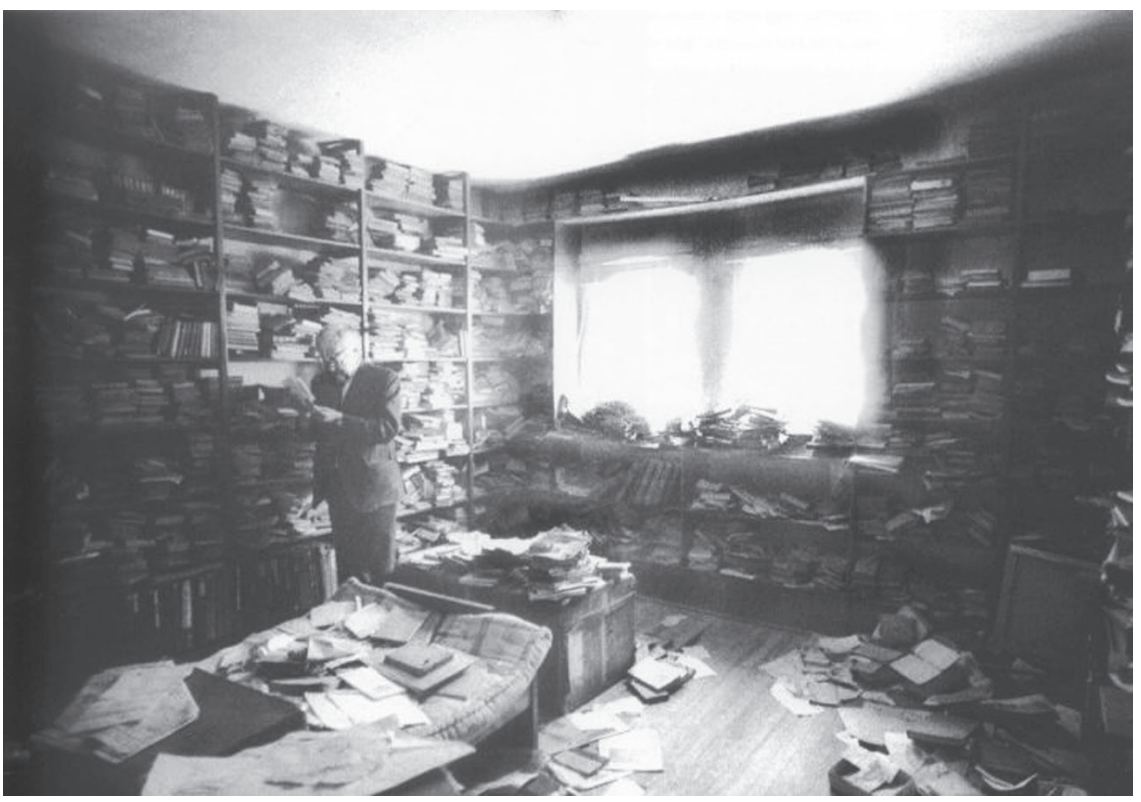

Figura 1. Fotografía de Abdu Eljaiek, tomada a León de Greiff en 1963.

Por

\section{Luisa Carolina Vélez Hurtado}

Universidad Distrital Francisco José de Caldas ${ }^{1}$ lcvelezh@correo.udistrital.edu.co

Resumen: Este artículo hace parte del proyecto de investigación "Página web de la historia de la fotografía en Colombia" de la Fundación Universitaria Los Libertadores. En él se desarrolla un estudio del retrato hecho en 1963 al poeta León de Greiff por el fotógrafo Abdú Eljaiek. Se utiliza una metodología basada en el análisis multimodal, con el fin de descifrar el sentido que dicha imagen adquirió en el contexto sociocultural en el cual fue creada (la sociedad colombiana de la década de los 60). Dicha imagen se escogió al ser un ícono de la historia de la fotografía en Colombia en el marco de la reportería gráfica, aunque el autor se formó y consolidó en el medio publicitario, al igual que la mayoría de fotógrafos de época. Esto permite deducir el prestigio que tenía la fotografía documental como una forma aceptada de arte y por ende como un modo de validar la práctica fotográfica, al adquirir reconocimiento social y en consecuencia ser recordados en el discurso historiográfico oficial. 
Palabras clave: fotografía, publicidad, análisis multimodal, reportería gráfica, análisis crítico del discurso.

\begin{abstract}
This paper is part of a research "Website of the history of photography in Colombia” carried out by Fundación Universitaria Los Libertadores. This article features a study of the portrait taken in 1963 of the poet León de Greiff by the photographer Abdú Eljaiek. Its methodology is based on the multimodal analysis in order to discover the meaning of this image in the sociocultural context of Colombia in the 60's. This image was chosen because it is an icon in the history of Colombian photography, despite its author was part of the advertising world, as well as the vast majority of photographers in that time. This allows us to deduce the prestige that documentary photography had as an accepted art form, and, therefore, as a means of validating the photographic practice, as it permits to acquire social acknowledgment and, consequently, to be remembered in the official history.
\end{abstract}

Keywords: Photography, advertising, multimodal analysis, graphic reportage, analysis of speech.

Resumo: Este artigo faz parte da pesquisa "Sítio da Web da história da fotografia na Colômbia” da Fundación Universitaria Los Libertadores. Nele se desenvolve um estudo do retrato feito em 1963 ao poeta León de Greiff pelo fotógrafo Abdú Eljaiek. Usa-se uma metodologia baseada na análise multimodal, com o fim de descifrar o sentido que essa imagem teve no contexto sociocultural no qual foi tirada (a sociedade Colombiana da década de 60). Dita imagem foi escolhida porque é um ícone da história da fotografia na Colômbia no marco do jornalismo gráfico, embora o autor foi formado no meio publicitário, o mesmo que a maioria dos fotógrafos da época. Isto permite deduzir o prestígio que tinha a fotografia documental como uma forma aceitada de arte e, portanto, como uma maneira de validar a prática fotográfica, ao adquirir reconhecimento social e, por consequência, um jeito de ser lembrados na história oficial.

Palavras-chave: Fotografia, publicidade, análise multimodal, jornalismo gráfico, análise crítico do discurso.

\title{
La fotografía como documento social
}

Desde su aparición, la fotografía ha revolucionado el uso social de las imágenes, puesto que permite la democratización de las mismas. Nace en un punto de la historia donde era necesario configurar un medio de reproducción que saciara las nuevas necesidades de comunicación de una sociedad industrializada, en donde la producción icónica deja de ser de uso exclusivo de un grupo privilegiado, y por el contrario pasa a constituirse como una práctica que refleja las nuevas dinámicas sociales marcadas por la burguesía, la cual promueve el culto a la individualización que va a tener su mayor expresión en el retrato, género heredado de la pintura Freund (1993). 
Adicionalmente, se debe tener presente que la fotografía tal como aparece en el siglo XIX, corresponde al afianzamiento de un proceso de la construcción de la mirada en occidente. Según Bourdieu (2003), la fotografía hereda la forma de representación de la realidad visible que se configura en Europa después del Quattrocento, no obstante, con el agregado que las fotografías se vuelven testigos de hechos ocurridos y por ende cumplen mejor su función de representación de la realidad. Sin embargo, con el paso del tiempo la fotografía no solo fue el medio objetivo para registrar, sino de presentarse y darse a conocer en una sociedad. La fotografía empezó a ser determinante en los procesos de integración social y a legitimar y solemnizar ceremonias y ritos sociales. En este orden de ideas es más relevante el poder de autentificación de la imagen fotográfica que su poder de representación, con lo cual podemos afirmar que el verdadero potencial de lo fotográfico está en los usos sociales que las comunidades del mundo le otorgan, al entenderla como un testigo de lo acontecido, fenómeno que se percibe con el nacimiento de la fotografía doméstica. Así mismo, la fotografía potencializó a una gran escala la comunicación por medio de imágenes, ya que al permitir múltiples copias de una misma imagen hizo que el aspecto de difusión se ampliara, causando que a este medio "objetivo" se le empezaran a delegar funciones relacionadas con la preservación de la memoria individual y colectiva. Por esta razón, la práctica fotográfica permeó la mayoría de las actividades sociales en el globo terráqueo al punto que ningún evento se consideró importante sino tenía un registro fotográfico.

Lo anterior lo podemos contemplar de un modo claro en la historia de la fotografía colombiana al analizar el retrato de León de Greiff producido para la prensa en los años sesenta, (pero publicado décadas posteriores en la Revista Semana) momento en el cual se consolida el medio publicitario y toma fuerza la reportería gráfica en el país. En esta época, la vida íntima de las personas no hacía parte de la esfera pública, con excepción de los individuos cuya intimidad, por su posición social o su producción científica, cultural o artística, era digna de ser registrada y distribuida para conocimiento de todo el colectivo social. Es relevante enfatizar en lo que significaba ser el protagonista de una foto en una publicación como la Revista Semana en el contexto de la vida ciudadana: "la práctica de la fotografía se toma como una manifestación de la voluntad de jugar al ciudadano, de enseñorearse”(Bourdieu, 2010, p.58). De esa manera la fotografía se convierte en una autentificación del prestigio social, al volver a la persona retratada en un personaje público, aun cuando dicho reconocimiento se diera muchos años después, de efectuada la toma.

\section{Abdú Eljaiek fotógrafo}

Según el historiador Boris Kossoy (2001) La fotografía es una imagen-objeto de una época definida, que está configurada por los siguientes elementos constitutivos: un asunto, un fotógrafo y una tecnología, que tienen una coordenadas de situación específicas (un tiempo - espacio determinados). Es decir, que la imagen es entendida

como un artefacto, una construcción estética, histórica y testimonial, que está mediada por un filtro cultural que es el fotógrafo. Se podría entonces afirmar que la imagen 
atestigua dos realidades distintas; la primera hace referencia al evento que registra en el pasado y la segunda nace en el momento que se materializa la imagen, la cual es fragmentada, interrumpida, aislada, discontinua e independiente del acontecimiento registrado. Esta segunda realidad tiene su propio significado e historia. Por consiguiente, el hecho que contenga dos realidades las hace fuentes ambiguas ya que son materia y expresión (testimonio/creación). "La fotografía aporta informaciones visuales sobre un fragmento de lo real, seleccionado y organizado estética e ideológicamente". (2001, p.90)

Teniendo en cuenta lo argumentando, la fotografía objeto de análisis del presente trabajo nos permite ver imaginarios sobre quién era digno ser fotografiado en la sociedad colombiana de las años sesenta; no obstante es sustancial contemplar otro aspecto fundamental para entender la producción fotográfica de aquellos años y esto es mirar a Abdú Eljaiek autor de la foto en cuestión, para lo cual se hará referencia a fuentes que brindan información sobre aspectos metodológicos de su obra; tales como la tesis de pregrado de Sánchez M. (2006), titulada: El ojo fotográfico de Jorge Silva y sus contemporáneos, tres artículos y una entrevista semiestructurada hecha en el año 2015. Abdú, oriundo de Calamar (Magdalena), con ascendencia libanesa pero radicado en Girardot; al igual que muchos otros fotógrafos, no había estudiado el oficio, lo aprendió en el camino cuando tuvo que trabajar como laboratorista para televisión, aunque este sí estudió en la Escuela de Bellas Artes de la Universidad Nacional de Colombia a su llegada a Bogotá; esto demuestra que en aquel entonces, la fotografía no era una actividad profesionalizada y que parte del trabajo de la generación de Eljaiek, sería defender la práctica como algo creativo y por ende susceptible de autoría. "cualquiera podía trabajar en publicidad, cualquiera que supiera recortar fotos estaba metido en publicidad" (Avendaño, Hernández y Vélez, comunicación personal, 01 de abril de2015) , De ahí la escogencia del documento visual a estudiar, puesto que es una toma que presenta varios de los rasgos característicos que este fotógrafo desarrollará a lo largo de su trayectoria y que constituirán un estilo personal e único, el cual le ayudaría a ser reconocido con el tiempo en el campo.

Por ejemplo, en la entrevista que Abdú concedió a Viviana Sánchez (2006), manifiesta tener sus propios parámetros para fotografiar cuando hace reportaría gráfica: "cómo mirar la gente, como verla, cómo actuar frente a la gente, observar qué expresiones hace en un momento dado y saber por qué las hace” (p.104). Para los retratos, emplea una técnica particular, él afirma que "se pone a charlar", acto seguido, en un momento de descuido captura el instante perfecto de los personajes a los que casi siempre conoce, por lo que tiene acceso a su intimidad (p.108). Lo anterior se reafirma cuando Eljaiek en esta misma conversación recuerda el estudio fotográfico que le realizó a León de Greiff, al contar que tenía cierta cercanía con el poeta, lo que le permitió entrar a su casa y estar al tanto del "reguero de cosas" que luego usó para hacer el retrato (Sánchez, 2006, p. 106). Por otro lado, en un artículo sobre el fotógrafo colombiano publicado en el diario EL TIEMPO en el año 2008, se hace alusión a este mismo suceso: 
Dentro de sus recuerdos de bohemia está el café El Automático en pleno corazón del centro de Bogotá adonde asistía a escuchar las tertulias del poeta León de Greiff. "El poeta bebía y leía poesía sin importarle el mundo exterior, una tarde le pedí una copia de un poema y lo acompañé a su estudio, en medio del desorden de escritos y libros, lo inmortalice en mi cámara” (Montaño, 2008).

Sumado a la captura de los gestos y poses de las personas fotografías, la luz y el espacio son rasgos determinantes en la práctica fotográfica de Eljaiek, pues acentúan una atmósfera de naturalidad, ya que se presentan como reflejos de la personalidad del retrato, lo que causa que varias de sus fotos pueden parecer oscuras o contrastadas, pero como él mismo ha sostenido, esto no se debe a un error, sino a su visión sobre el personaje retratado. Motivo por el cual fueron rechazadas sus imágenes en diarios y revistas de la época. "Entonces le dicen a uno que la foto le quedó oscura y yo digo que sí está oscura, pero no me quedó oscura, yo la hice asi”” (Sánchez, 2006, p. 103).

Bajo esta perspectiva, se puede inferir que Abdú ha cultivado "un modo de ver" (Berger, 2001) que es el producto de la negociación entre una estética propia y una estructura que validada esa forma particular de fotografiar. Así, aunque la fotografía es el resultado de la huella luminosa de la presencia de algo o alguien, esto no significa en ningún momento lo identifique o lo represente en términos de lo real, ya que la imagen fotográfica propone un distanciamiento tanto en el tiempo como en el espacio con su referente, lo que permite que el acto fotográfico siempre esté constituido por las acciones que se ejerzan antes y después de la toma y que están inscritos en la generación de sentido, a saber codificados en un orden cultural y social.

Lo previamente expresado ha sido tratado por el autor francés Philippe Dubois, quien publicó el que hoy es considerado una de los libros más relevantes sobre la fotografía El Acto Fotográfico. Este ensayo cobraría relevancia con el tiempo puesto que, Dubois evidencia los problemas que se tienen al considerar a la fotografía como un índice o huella de la realidad. Se ve pues que si el index fotográfico, más que cualquier otro medio de representación, implica en algún punto una fuerza, un poder, una plenitud de lo real, éste opera sólo en el orden de la existencia y en ningún caso en el orden del sentido. El index se detiene con el «eso ha sido». No llena el lugar de «eso quiere decir». La fuerza referencial no se confunde con ningún potencial de verdad. (Dubois, 1986, p.81).

En este contexto, el retrato del poeta León de Greiff a pesar que se inscribe dentro de una categoría documental, tiene un discurso que se constituye a su vez por el ojo del fotógrafo y sus determinaciones, como por los medios de comunicación por el cual ha sido difundido. 


\section{El análisis multimodal como una herramienta de análisis para documentos fotográficos}

Los fundamentos metodológicos utilizados para la interpretación de la fotografía objeto de análisis se enmarcan en el "Análisis multimodal. Los modos y los medios de la comunicación contemporánea”, soportados en la teoría de la comunicación multimodal desarrollada por Kress \& van Leeuwen (2001). Esta teoría de análisis se inscribe dentro del Análisis Crítico del Discurso (ACD), la cual trabaja tres áreas fundamentales: poder, historia e ideología desde una perspectiva sociocultural. La teoría sobre lo multimodal busca hacer un análisis transversal a los diversos tipos de discursos, como resultado del cambio de producción monomodal a multimodal, debido al desarrollo de nuevas tecnologías de creación y distribución en donde los principios comunes de la semiótica operan de forma cruzada en el acto comunicativo. Así pues, la investigación se realiza de una manera integral, puesto que todos los modos semióticos tienen el mismo valor para transmitir significado o construir sentido dentro de un contexto social y cultural específico. Luego, esta metodología puede ser vista como una valiosa herramienta para el análisis de documentos fotográficos, al no aislarlos sino al estudiarlos en conjunto con todos los factores de su ambiente de publicación; motivo por el cual fue escogida para el desarrollo del presente trabajo.

La teoría multimodal propone un paso de la idea del lenguaje de los múltiples medios a la idea de comunicación. Kress \& van Leeuwen definen la comunicación "como un proceso en el que un producto o evento semiótico es articulado o producido e interpretado o usado”(2001, p.12). La multimodalidad propone un análisis de las especificidades y los rasgos comunes de los modelos semióticos y cómo estos de una manera conjunta participan en la producción discursiva. Kress \& van Leeuwen observan textos multimodales como constructores de sentido en múltiples articulaciones, identifican cuatro estratos de la práctica en los que predomina la adjudicación de sentido: discurso, diseño, producción y distribución. Estos estratos no tienen un orden jerárquico, pues adquieren igual relevancia para dar significado en un análisis global:

El Discurso. En primer lugar es el dominio general de todas las declaraciones y en segundo lugar es un grupo individualizable de declaraciones. Cualquier declaración o texto es un discurso o conjunto de declaraciones unidas por unas características internas que las hacen coherentes. Para Kress \& van Leeuwen (2001) "los discursos son conocimientos socialmente construidos de (algún aspecto) de la realidad” (p.3).

El Diseño. El concepto de diseño es inherente a la propuesta del discurso multimodal, es decir que este es un bosquejo conceptual y abstracto del discurso antes de ser materializado y por ende utiliza modos semióticos abstractos para planear la producción de los eventos semióticos finales. Por consiguiente, el diseño permite entender los discursos en el contexto comunicativo ya que para este estrato la interacción social tiene una gran influencia debido a que puede cambiar la materialización del discurso según el contexto sociocultural en el que van a circular. 
La Producción. Es el estrato en el cual se materializa en evento semiótico el diseño, es la etapa en que se vuelve perceptible el significado, sin que esto quiera decir que sea la etapa final, ya que aunque existe puede cambiar aún más en el proceso de distribución. En la producción juega un papel muy importante las cualidades físicas del material (color, textura, dimensiones, soportes, etc), que contribuyen a la creación de sentido y pueden modificar el diseño original, ya que se pasa de lo conceptual a lo físico.

La distribución. En este estrato se le da relevancia a las tecnologías de la reproducción y recodificación de los eventos semióticos como estrategia para ser percibidas por un colectivo social amplio. La distribución es capaz de dar matices de sentido significantes en la comunicación final del discurso, por ejemplo, no es lo mismo ver una pintura en óleo sobre lienzo en un museo, que fotografiada y copiada en un libro de arte, puesto que hay una recodificación del significado comunicado. A continuación se presentan los resultados dados por la indagación hecha a la pieza en cuestión por medio de la secuencia de los cuatro estratos propuestos por el análisis multimodal: discurso, diseño, producción y distribución.

\section{Hallazgos y discusión}

\section{Discurso}

Para el análisis del discurso de la fotografía en cuestión se tomaron en cuenta diferentes aspectos como la biografía de León de Greiff; adentrándose en su vida personal y en características como su timidez, su desorden de libros; así como el concepto de la Revista Semana y la editorial de la misma, el público objetivo de esta publicación, la época y su contexto histórico en la sociedad colombiana. Todos estos aspectos se estudiaron desde un enfoque integral para darle significado a cada detalle de los diferentes elementos y modos que componen la imagen fotográfica.

El discurso que maneja el concepto de la foto hecha en la década de los sesenta, es mostrar un personaje intelectual de la vida nacional, considerado como uno de los más destacados escritores del siglo XX en Colombia, rodeado de su mayor riqueza "sus libros", mostrando a un individuo inmerso en sí mismo. La foto no pretende degradar su vida, por el contrario, está orientada a exaltar la sencillez de una personalidad como de Greiff en su ambiente, engrandeciendo su vida ante la sociedad al pasar a ser un personaje reconocido en la vida pública de Colombia. La foto rompe esquemas por el concepto del discurso que manejó en su realización, al mostrarle a la sencillez de la vida de un escritor y poeta, promoviendo su popularidad y el reconocimiento de los colombianos. Es importante mencionar que tan solo un año después de tomada la fotografía, León de Greiff recibe uno de los reconocimientos internacionales más significativos para su vida como poeta e intelectual "La Estrella del Norte", otorgado en Suecia en 1964. 
El discurso que maneja la fotografía contrasta con el imaginario de la sociedad, al pensar que un intelectual y poeta con reconocimientos nacionales e internacionales debería tener una vida cómoda, vivir en una casa lujosa y gozar de comodidades, pero el fotógrafo buscaba evidenciar el modus vivendi de un personaje de esta naturaleza, donde sus libros son su mayor riqueza. La toma no pretende ridiculizar la vida del poeta, por el contrario, el discurso de la imagen está orientado a exhibir a de Greiff como un personaje sencillo en su realidad cotidiana rodeado de sus pertenencias, pues la fotografía le fue hecha de manera desprevenida cuando buscaba un libro sin que él se enterara, sin luz artificial, y fue publicada tal cual en blanco y negro sin ningún tipo de retoque.

Esta imagen es sui géneris para el contexto de las fotos que se publicaban en las revistas de la época de su creación, pues el estilo de fotografías difundidas de reconocidos políticos como Carlos Lleras Restrepo u otras personalidades de la vida pública, eran fotos muy bien planeadas, encuadradas, con iluminación artificial y editadas para transmitirle al público la imagen y proyección de estos personajes a la sociedad colombiana. La foto de León de Greiff contrasta con esta línea habitual o convencional, porque es una foto espontánea que permite el desorden como el común denominador y el personaje retratado pasa a un segundo plano para el observador, invitando a adentrarse en los detalles para descubrir muebles y objetos cubiertos por libros como una "cama con un colchón” en medio de una biblioteca.

En síntesis, esta comparación del concepto discursivo de las fotos de personajes de la época de los 60's nos permite afirmar que los editores de prestigiosas revistas como Semana, no autorizarían la publicación de la foto sobre la vida de un escritor y poeta inmerso en su desorden cotidiano. A pesar de la cercanía que este, no sólo tenía con los colaboradores (su hermano Otto) sino con el propio fundador de la revista Alberto Lleras Camargo, quien siendo presidente de la república en el año 1958 lo nombró secretario de la embajada Colombiana en Suecia. Igualmente, hubiera sido poco probable que se tuviera en cuenta este mismo modo de fotografiar aplicado a ilustrar la vida de un político o un personaje científico, lo que se puede deducir al estudiar varios ejemplares de la revista de la época. Es pertinente señalar que el retrato de León de Greiff fue tomado 1963, como lo atestiguan varios documentos que mencionan la imagen en cuestión, siendo el caso del libro La historia de la Fotografía en Colombia (2006) escrito por el crítico e historiador de arte Eduardo Serrano. No obstante, como se sabe por testimonio del propio Eljaiek, quien en un artículo del año 2015 indica sin hacer claridad en cuál medio, que esta fue publicada después de 20 años de hacer sido hecha. "Nadie quería publicarla por oscura y hoy es la más recordada del maestro” (Salazar, 2015). En este orden de ideas es factible pensar que su única aparición en una revista como Semana, se diera en una edición especial dedicada a la historia de la fotografía en Colombia, titulada: Colombia Expuesta, Fotos con historia, del año 2008, en la sección Personajes, dedicada a retratos de personalidades del país reconocidas en diferentes ámbitos, pero cuya escogencia estuvo marcada por la peculiaridad y creatividad de las tomas más que por la importancia de las personas 
fotografiadas. Este ejemplar contó con un comité asesor conformado por reconocidos críticos e investigadores; el ya nombrado Eduardo Serrano, Armando Silva, Jaime Cerón y Camilo George.

Por ende, esta fotografía tuvo que esperar cuarenta y cinco años para ser publicada en un reconocido medio impreso. Pues como ya se ha sustentado, esta no correspondía a los paramentos estéticos y visuales de su momento. A pesar del hecho que en ese instante el fotógrafo Abdú ya trabajaba en el medio publicitario, y editorial, como lo demuestra que para la década de los setentas hay varias carátulas de la Revista Cromos con el crédito de su autoría y así mismo en las lecturas dominicales del el Diario el Tiempo.

En conclusión la validación de esta imagen llegará no por el campo de la reportería gráfica como tal, sino por el ámbito artístico, porque como ha sido revelado por autores como Santiago Rueda (2008), Eljaiek fue de los primeros fotógrafos independientes del país que empezarán a visualizar su trabajo de distintas formas incluyendo exposiciones es espacios dedicados al arte:

En los años sesenta, junto al desarrollo económico del país, toman forma la crítica de arte, los museos de arte moderno y las galerías. Nereo López, Hernán Díaz y Abdú Eljaiek surgen como los primeros fotógrafos independientes del país. Los tres serán fotógrafos editoriales, los primeros en publicar libros como autores y en realizar exposiciones individuales. (Rueda. 2008, 116)

Muy seguramente, este sería el motivo que llevó a Eduardo Serrado a incluir está foto dentro de su visión de la Historia de la Fotografía en Colombia, el cual fue editado dos años antes del ejemplar de la revista Semana. Lo que causaría asimismo que los defectos o errores que alguna vez fueron señalados en la imagen, sean finalmente reconocidos como elementos estéticos que representan de un modo más cercano y familiar a uno de los poetas más importantes en la historia del país, por encima de muchas otras fotografías que si fueron aceptadas en los distintos medios impresos del momento.

\section{Diseño}

En este caso tanto el diseño como la producción son realizados por el fotógrafo, aunque es de aclarar que no siempre es así y depende del tipo de producción fotográfica se haga, ya que en casos inscritos en la publicidad el proceso de diseño muchas veces no depende del fotógrafo en sino de un equipo de creativos. La imagen que se analiza en el presente trabajo se inscribe dentro de la fotografía documental, en donde es frecuente que estos dos estratos sean desarrollados por una sola persona.

El retrato fotográfico de León de Greiff, es una imagen que para su ejecución, el autor debió tener varios conceptos o convenciones sociales y culturales de cómo se debía hacer una fotografía de carácter documental. En los años sesenta varios fotógrafos latinoamericanos acogieron las pautas establecidas por la Agencia Internacional Magnum, 
fundada por el fotógrafo francés Henri Cartier Bresson en el año de 1947. Algunas de estas directrices hacen hincapié en trabajar exclusivamente con luz natural y no alterar las condiciones lumínicas de la toma, además de no editar ni retocar las fotos en procesos de postproducción y así como no dirigir el encuadre de la misma. Por consiguiente, lo que estas pautas buscaban era poder conseguir una imagen final donde el fotógrafo tratará de captar la espontaneidad del momento, lo cual fue nombrado por el mismo Bresson como "el Instante Decisivo".

En la pieza examinada se ha encontrado varias de las reglas descritas anteriormente y que está reafirmado por las declaraciones del autor, donde manifiesta que el método utilizado en las fotografías consistía en no presionar al retrato y por el contrario observaba pacientemente a que algún gesto o movimiento que fuera característico del mismo emergiera espontáneamente. No obstante, el hecho que el fotógrafo Abdú tratara de no intervenir de una forma directa sus tomas, no significa que en estas no haya una comunicación de consensos sociales de cómo se debía representar a los personajes retratados, lo cual muchas veces no es un acto consciente del fotógrafo. Efectivamente, una influencia que se puede percibir en la obra de Abdú y que corresponde también a lo descrito, es la estética instaurada por el fotógrafo colombiano Leo Matiz, quien fue maestro de Eljaiek en su periodo inicial, siendo Matiz uno de los fotógrafos con mayor reconocimiento internacional en la historia del país. El 8 de agosto de 1951, el crítico de arte Casimiro Eiger, en una de las emisiones radiales de su programa en la radiodifusora Nacional, comentó la obra de Matiz y sintetizó su trabajo en cuatro elementos estilísticos: "la eliminación casi completa del detalle enojoso, del motivo incidental, [pues] Matiz no reproduce objetos, sino formas; [el] rechazo a las conquistas técnicas de la fotografía que lo apartan del puro documento; [la] monumentalización de las formas; [y el] carácter psicológico de sus retratos”. Bien describe Eiger el trabajo del fotógrafo y su estilo que, como podremos ver más adelante, seguirá siendo aplicado por fotógrafos posteriores, especialmente por los que vuelven al documento social como tema en la década de los años setenta (Rueda, 2008, 116).

En el libro titulado Reading Image. The Grammar of Visual Design. Kress \& van Leeuwen (1996) definen la composición de una imagen como un modo de crear significado por medio de la distribución que se realiza en el espacio de los elementos que aparecen en un encuadre determinado. Según los autores hay tres factores determinantes para entender la composición de una pieza visual y estos son, Information Value, Salience and Framing. Teniendo en cuenta estos conceptos para analizar el estrato de diseño en la pieza en mención se pudo concluir que el fotógrafo tenía un imaginario de qué elementos eran representativos del personaje retratado y buscó que estos aparecieran en la imagen (los libros, la abundancia de estos, la soledad y el desorden). Para enfatizar que la imagen es hecha en la intimidad del personaje retratado, el fotógrafo decide hacer una composición horizontal en donde por el tamaño, el poeta no se destaca sino por el contrario se vuelve un elemento del paisaje, ya que al elegir una toma horizontal se destaca el contexto y no la persona como ocurre en una toma vertical (Ver Figura 2). 
Otro elemento que ayuda crear la idea de paisaje en la foto es el foco, puesto que éste aunque es un poco más definido en la zona donde está el poeta, en general maneja una nitidez pareja y no hay un desenfoque que llame la atención sobre algún elemento en especial, lo cual es un recurso usado normalmente en la fotografía de paisaje.

Al leer la pieza de izquierda a derecha como es usual en occidente, a la derecha encontramos en el primer tercio de la imagen al personaje; los otros dos tercios están centrados en mostrar la habitación. Siguiendo con lo explicado por Kress \& van Leeuwen (1996), en la derecha se ubica generalmente lo conocido o lo aceptado socialmente como un conocimiento dado y en la izquierda se ubica lo nuevo, lo que es significativo en la imagen, que en este caso sería el ambiente íntimo del retratado, que nos muestra su soledad y su introspección en su oficio de poeta. Otro componente que se destaca de izquierda a derecha es la luz, la cual resalta desde el centro hacia la izquierda de la composición y por lo contrario en la parte derecha en donde está el personaje, hay penumbra en la escena. La luz que proviene del exterior no nos permite ver ningún detalle del paisaje fuera de la foto, lo que en oposición reafirma el aislamiento del poeta del contexto social fuera de sí.

De igual modo, si se observa la imagen de arriba abajo en la parte inferior se destaca el desorden, especialmente los libros tirados encima de la cama y en la parte superior se destaca el techo como un espacio en blanco y el orden de las estanterías de la biblioteca. En relación con lo estudiado por Kress \& van Leeuwen (1996), los elementos que generalmente se ubican en la parte inferior de la composición hacen referencia a lo real y lo ubicado en la parte superior a lo ideal.

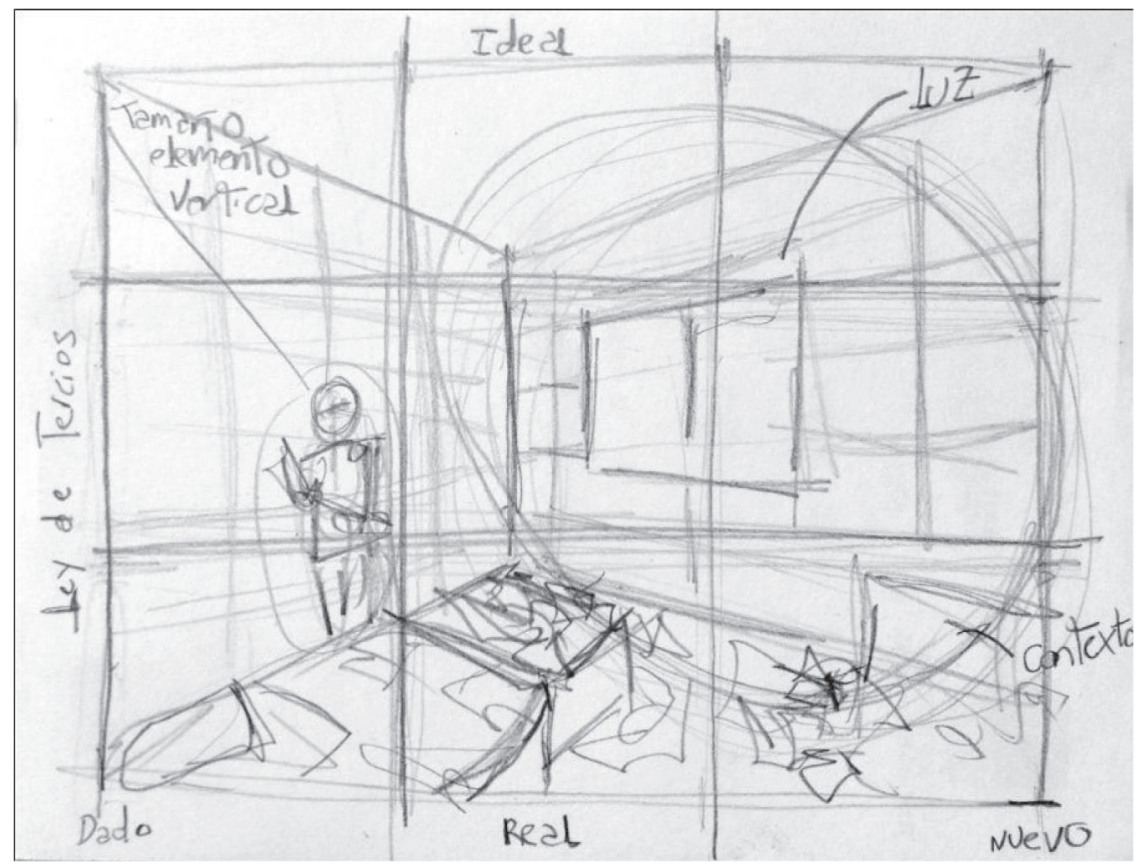

Figura 2. Boceto a Papel y Lápiz de la Fotografía de Abdú Eljaiek. Elaborado por Luisa Carolina Vélez (2015) 
Por tal motivo, el retrato de León de Greiff fue hecho con el propósito de mostrar a los observadores de la pieza un carácter íntimo y desconocido del autor, ya que si lo comparamos con otras fotos hechas a este, ninguna es capaz de resaltar efectivamente varios aspectos de la personalidad de este intelectual, siendo reafirmado al ser una imagen de tipo documental en donde queda resaltada la naturalidad del personaje al buscar un libro a espaldas de la única fuente de luz. Lo anterior, también ha sido observado por Andrés Serrano (2006) al hablar de las diferencias entre las formas de retratar entre Hernán Díaz y Eljaiek :

Un caso opuesto lo constituyen los retratos de Abdú Eljaiek- quien se había iniciado en la fotografía en la segunda mitad de los años cincuenta-, no sólo porque involucran el espacio que circunda a los personajes, sino porque este espacio está por lo general constituido por su entorno más característico: Caballero Calderón y León de Greiff en sus perspectivas bibliotecas, Enrique Buenaventura en un escenario, Olaf Roots dirigiendo la Orquesta sinfónica Nacional, y así sucesivamente, cada individuo inmerso en su propio mundo, vinculado con su arte o su oficio, de manera que se incremente la información sobre sus logros y carácter. (p..24)

\section{Producción}

La Fotografía es hecha con una cámara reflex formato $35 \mathrm{~mm}$, el cual es un medio pensado para la reportería gráfica por su tamaño, puesto que en medios impresos como periódicos y revistas las impresiones no son de un gran tamaño. La escogencia de este formato también incide en el carácter rectangular de la composición y hace que siempre la foto tenga una preponderancia de un solo sentido, sea vertical u horizontal que es el caso de esta imagen.

El autor decidió trabajar con un lente gran angular entre 25 y $28 \mathrm{~mm}$, el cual le permitió tener un mayor detalle y foco general en la imagen, además un ángulo de visión (entre 75 y 82 grados) superior al normal del ser humano que es de 46 grados. Estas decisiones se corresponden con lo previsto en el diseño ya que se corresponde con la metodología usada en fotografía de paisaje más que en la utilizada para hacer retrato con el de integrar al personaje central con su entorno.

Una de las características fundamentales en la producción de esta imagen, es el hecho de que es realizada a blanco y negro, lo cual se convierte en un modo semiótico transversal en el significado transmitido por la misma. La foto es realizada con una película TMax ISO 400, que por la sensibilidad a la luz la hace granulada. Este tipo de magazín es usado cuando la fuente de luz no es muy abundante, lo que ratifica que el ambiente donde se tomó la imagen no es muy luminoso pero demuestra el interés del fotógrafo de no alterar la escena al usar una luz artificial. 
El uso del blanco negro puede estar relacionado con varios factores, unos de carácter técnico ya que la mayoría de las impresiones de las revistas se hacían por motivos económicos en una sola tinta, con excepción de la carátula y de las imágenes publicitarias, que usualmente si se imprimía a color y en una mejor material. El otro factor es de carácter estético, porque el blanco y negro sin importar la aparición de la tecnología para hacer tomas a color, se convirtió en una de las características de la fotografía documental, al permitir que todas las formas que aparecían en la imagen fueran igualadas a un mismo nivel lumínico y de este modo no se crearán distractores en la lectura por contraste de color. Además el uso del blanco y negro permite acentuar aún más la distinción entre el referente fotografiado y la imagen final por medio del color neutro y así crear un tiempo distante sin referente en el presente. La fotografía a blanco y negro tiene la propiedad de hacer solemne el tiempo al acentuar el carácter de pasado que posee de por sí la imagen fotográfica. En definitiva el uso del blanco y negro permite al fotógrafo centrarse en la luz y su intensidad, la cual por su fuerza produce un claroscuro que divide la escena en dos y permite afirmar aspectos de la vida del personaje retratado.

Por último, no hay que olvidar que la fotografía es un medio pensado para ser reproducido, que la forma como se produjo es susceptible a cambios en su materialidad en la distribución de la imagen y lo cual hará que aspectos estéticos de la misma varíen o desaparezcan en las múltiples copias hechas en sustratos diversos como lo son, la prensa de distintas épocas o el internet en la actualidad.

\section{Distribución}

Los modos semióticos constituyen un conjunto de alternativas para producir significados que han sido formados en función de las necesidades de la vida social y que conforman el potencial comunicativo de una cultura. Diversas investigaciones se han abocado al estudio de las características específicas de los diferentes modos semióticos, como la de Kress \& Van Leeuwen (1996) donde los modos semióticos son usados por un grupo cultural para producir significados.

La característica central del modo semiótico es la materialidad. El recurso o modo para significar es moldeado por un grupo cultural alrededor de las limitaciones y potencialidades de la materialidad de su o sus rasgos materiales o físicos elementales (luz, color, espacio, etc.). Es decir, cada recurso se provee potencialmente de distintas formas de representar y comunicar significados, las que dependen en primera instancia de la materialidad de dicho modo semiótico y las posibilidades que ofrece para la forma de actividad, conducta o proceso que involucra signos. Es por esto, por ejemplo, que la lengua oral y la lengua escrita sean conceptualizadas en esta perspectiva como recursos distintos, ya que su materialidad ofrece potencialidades distintas para la creación de significado.

Dada la pertenencia a un grupo cultural, las formas y contenidos de significación parten de una base compartida, por lo que se puede hablar de reproducción de los significados. Sin embargo, también hay transformación de los mismos, producción de sentidos muy 
particulares a partir del conjunto de signos y herramientas que conforman un espacio social, lo cual se da a través de las acciones de los participantes que los usan de formas específicas. De esta manera, el análisis toma en cuenta la tensión existente entre la reproducción del significado culturalmente predominante y su transformación en formas particulares de producción. Los modos que se consideran para el análisis en este trabajo incluye: acción, gestos, miradas, describir las distancias medibles entre las personas mientras éstas interactúan entre sí, postura corporal, posición y desplazamiento espacial. Estos son modos semióticos cuyo sustrato material es la actividad del cuerpo y a través de ellos es que Abdú Eljaiek establece interacciones en y con el espacio. Se analiza también el diseño de la biblioteca, los libros, el desorden, la cama y su distribución en el espacio, los cuales son modos semióticos descorporizados, producto de la actividad social objetivada. Las interpretaciones de los significados en este pieza consideran, por un lado, el conocimiento producido y reportado en la literatura acerca de cada modo semiótico y, por otro, las perspectivas del autor en tanto un grupo cultural específico experimentados en la vida social escolar; sin embargo, la elaboración de las interpretaciones tiene como base fundamental la consideración del contexto mismo en el que se producen.

La distribución de la imagen se ha realizado en varios medios de carácter impreso y digital. Aquí destacamos dos páginas web en particular por el sustancial papel que han jugado en la percepción de la imagen y su influencia en el modo como ha sido asumida en publicaciones posteriores (Figuras 3, 4 y 5).

Uno es ColArte (Figura 6), un lugar exclusivo para publicar lo mejor que tiene el arte en Colombia, en donde presentan la foto del poeta acompañado del mismo texto publicado en la revista Semana (2008) y el otro, es el sitio web del Museo Nacional de la Fotografía, FOTOMUSEO. (Figura 7), en el cual está la imagen en cuestión a modo de memoria de una exposición conmemorativa de la obra de Abdú Eljaiek en el año de 2009, en el marco del evento Fotográfica Bogotá; sto fue tan solo un año después de publicado el ejemplar Colombia Expuesta y a tres años de haber sido lanzado el libro de Eduardo Serrano, quien destaca el trabajo del maestro como retratista, justamente el tema del evento organizado por FOTOMUSEO ese año.

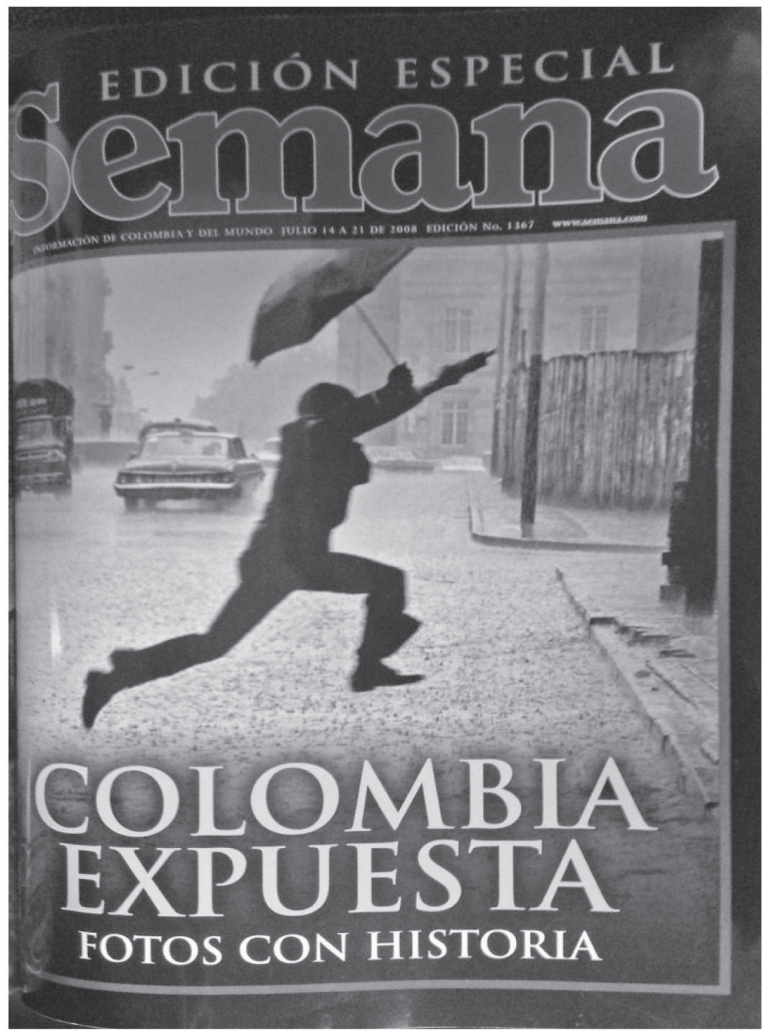

Figura 3. Revista Semana (2008) 

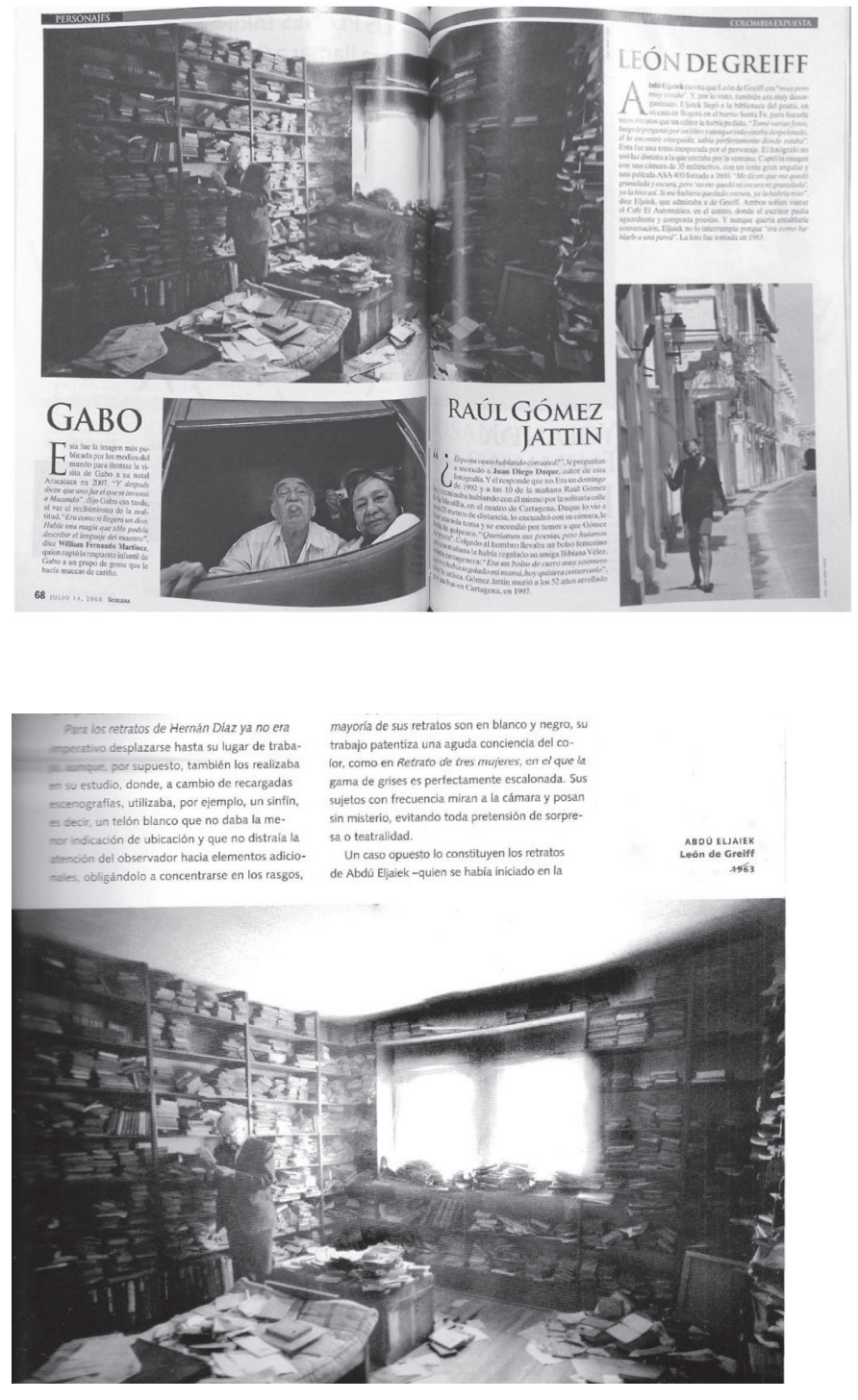

Figura 4. Fotografía de Abdu Eljaiek tomada a León de Greiff en 1963. Publicación Revista Semana Edición Agosto 2008
Figura 5. Fotografía de Abdu Eljaiek tomada a León de Greiff en 1963.Publicación Libro Historia de la Fotografía en Colombia 2001

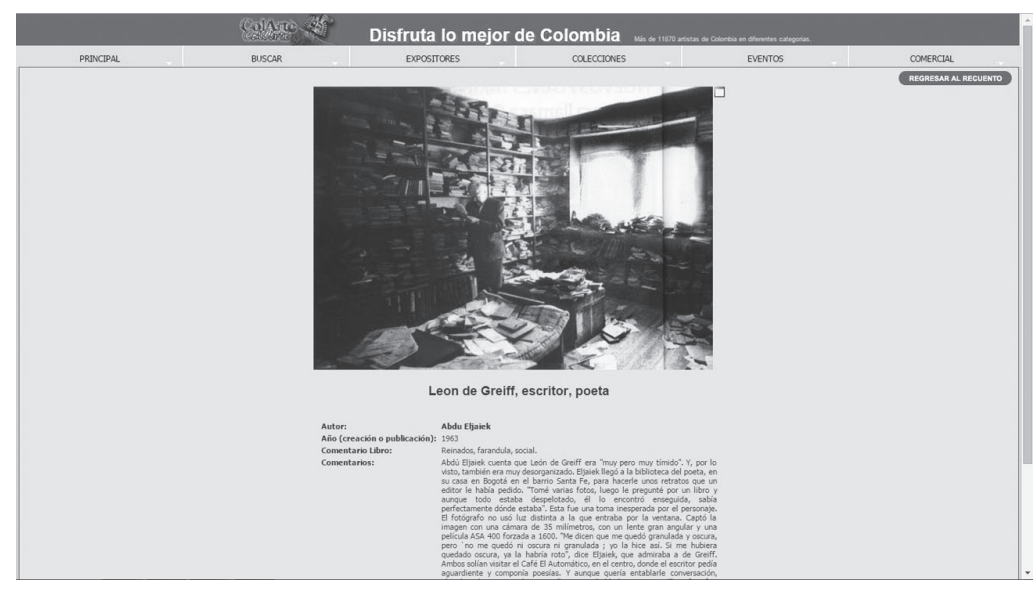

Figura 6. Pantallazo Fotografía de Abdu Eljaiek tomada a León de Greiff Disponible en: http: / / www.colarte.com/colarte/foto.asp?idfoto=259956 Publicación Libro Historia de la Fotografía en Colombia 2001 


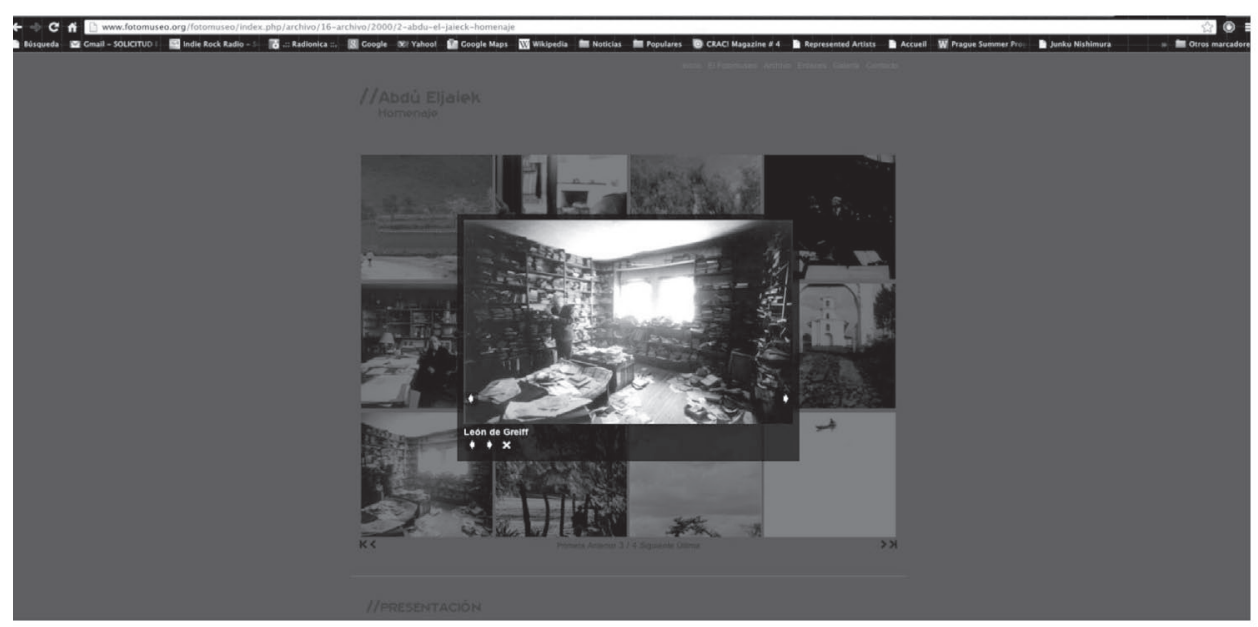

Figura 7. Pantallazo Fotografía de Abdu Eljaiek tomada a León de Greiff.

Disponible en: http: / /www.fotomuseo.org/eljaiek/presentaciongilma.htm

\section{A modo de conclusión}

Abdú Eljaiek es un fotógrafo que se formó dentro del ámbito de la fotografía publicitaria, sin embargo su producción más reconocida y recordada está vinculada a la fotografía documental, de la cual es una muestra la foto del poeta León de Greiff examinada en este trabajo. Lo anterior expuesto, se debe al valor social que se le da a la práctica fotográfica según el campo en el que se enmarca; que en el caso de la imagen publicitaria de aquel entonces (décadas sesenta y setenta) al no ser reconocida como un acto creativo o testimonial, no se le otorga un mayor valor estético; al contrario de la fotografía documental, que en ese momento se vinculaba a la representación de hechos reales de interés nacional, que son capturados por el modo particular de ver un individuo. Por tal razón los fotógrafos que querían consagrarse como tal debían hacerlo por medio de la reportería gráfica. De ahí que no sea extraño que la fotografía documental haya sido estimada en la historiografía de la fotografía en Colombia como un modo válido dentro del ámbito artístico y por ende susceptible de ser reconocida su autoría, como lo han sustentado autores como Santiago Rueda (2012).

AE: acá nunca la fotografía fue arte, aquí la fotografía era un papel con una imagen ahí, y al que consideraban fotógrafo era el que iba a las primeras comuniones, matrimonios, esos eran fotógrafos.

LV: ¿Fue cuando la publicidad comenzó a cambiar eso?

AE: En parte sí, pero, no le dieron categoría en ese momento, entonces Hernán Díaz y yo, nos propusimos a decir: "la fotografía es arte, entonces nos respetan, no me cortan las fotos, todo eso”. Es que un diseñador de una revista, cogía la foto y la recortaba, le ponía títulos encima, si ningún respeto, porque la fotografía es un papel.

(Avendaño, Hernández y Vélez, comunicación personal, 01 de abril de2015) 
Tal vez lo expuesto se deba principalmente a que cuando empieza a usarse de manera permanente la fotografía en el ambiente publicitario del país, en decir en la década de los sesenta, era normal que se copiaran los referentes extranjeros; en consecuencia los fotógrafos eran ejecutores más no agentes propositivos del campo. No obstante, Abdú hizo parte de una generación que lentamente empieza a proponer sus propias ideas, sus propias propuestas visuales. Así pues, son estos fotógrafos los que realmente inician la historia de la fotografía publicitaria en Colombia. Muestra de esto es el hecho que Abdú junto con otros colegas comenzaron a exigir que sus créditos autoriales fueran colocados en las distintas publicaciones, como lo prueban varias de las carátulas de la Revista Cromos de los años setenta en donde se puede observar el nombre de Eljaiek, el cual afirma al respecto:

Sí, pero yo seguí trabajando con agencias y todas eran lo mismo y habían (sic) ciertos resquemores, ciertos roces, porque yo hice amistad con Eduardo Mendoza Varela, en el Tiempo, cuando él era Director de Lecturas Dominicales y él prefería que fueran mis fotos las que salieran, las que se publicarán allí, no siendo yo empleado de ElTiempo, entonces me publicaban las fotos mías, o publicaban alguna foto publicitaria de lo que yo hacía, y hablaban del fotógrafo, no del creador, no hablaban del ejecutivo de la empresa, hablaban de mí. (Avendaño, Hernández y Vélez, comunicación personal, 01 de abril de2015).

Al comparar la producción publicitaria y documental de Eljaiek vemos cómo el modus operandi cambia, el manejo del color, de la proporción, la composición, los personajes retratados y las poses son completamente disímiles, al igual que el tratamiento de las imágenes dentro de las publicaciones, puesto que, por ejemplo en la fotografías de orden documental si había de manera generalizada y no solo en las carátulas, como ocurría en la foto publicitaria, el reconocimiento de los créditos autorales. El autor Eguizábal, quien es reconocido por su estudio de la fotografía publicitaria, argumenta en relación de las diferencias entre estos dos géneros que:

En las imágenes publicitarias el sentido preexiste a la fotografía, es decir, responde a una estrategia.Y ello las separa de las fotografías documentales, del fotoperiodismo, de la fotografía «verdad». El fotógrafo publicitario realiza una serie de tomas para ver cuál se ajusta mejor a la idea original. Incluso podemos repetirlas hasta conseguir el «efecto deseado». Todavía más, retocamos la «realidad» (la posición de la modelo, la ubicación del producto) hasta conseguir el efecto. La otra se basa en el «instante decisivo». (Egizabal, 2005, p.88)

Es decir que el fotógrafo asume en su quehacer las normas vigentes en cada contexto y se adaptada a las mismas, sin que esto signifique que este no sea capaz de ser propositivo y desarrollar un estilo propio, de ahí la pertinencia del análisis multimodal, pues es una metodología que permite revelar las leyes culturales, sociales e históricas que influyen en la conformación de lo visual y que no son perceptibles a simple vista. "Ninguna imagen significa nada por sí misma. Es en el uso social que una imagen adquiere significado, en correspondencia con el modo de ver que se ponga en funcionamiento". (Goyeneche, 2009, p. 31) 
A modo de conclusión podríamos afirmar que así como un fotógrafo es capaz de forjar una gramática visual propia, esto es, un estilo propio y único, como lo demuestra el maestro Abdú en su reportería gráfica, el mismo fotógrafo sería capaz de hacer lo mismo pero el campo de la fotografía publicitaria, que aunque sea un género fotográfico donde muchas de las decisiones ya están decididas antes de la toma, el fotógrafo puede aun así crear una manera particular de hacer la imagen. Lo expresado sería una inquietud pertinente que se puede desarrollar en futuras investigaciones sobre la fotografía publicitaria en Colombia, puesto que ayudaría a identificar tendencias y modos de hacer específicos de cada época, además de ayudar a identificar a esos personajes como Abdú Eljaiek que hicieron posible la fotografía publicitaria en el país y que dado el poco valor social que se le ha asignado, no han podido ser reconocidos en la historia de la fotografía en Colombia.

\section{Notas}

${ }^{1}$ Maestra en artes plásticas y Visuales, Facultad de Artes ASAB, Universidad Distrital Francisco José de Caldas. Especialista en fotografía, Universidad Nacional de Colombia. Aspirante a magíster en Comunicación Educación, Universidad Distrital Francisco José de Caldas

\section{Referencias}

Berger, J. (2001). Modos de ver. Barcelona, España: Editorial Gustavo Gili.

Bourdieu, P. (2003). Un arte medio: Ensayo sobre los usos sociales de la fotografía. Barcelona Gustavo Gili.

Bourdieu, P. (2010). El sentido social del gusto. Elementos para una sociología de la cultural. Siglo Veintiuno Editores, Buenos Aires, Argentina.

Dubois, p. (1986). El acto fotográfico de la representación a la recepción. Barcelona, España: Paidós.

Eguízabal, R. (2005). La fotografía Publicitaria en El Análisis de la Fotografía Publicitaria. Publicacions de la Universitat Jaume I, Madrid.

Freund, G. (1993), La fotografía como documento social. Barcelona, Gustavo Gili.

Goyeneche, E. (2009). Fotografía y Sociedad. Medellín: La carreta editores. E.U.

Montaño. J. (31 de agosto de 2008) La historia inédita de Colombia según el fotógrafo Abdú Eljaiek. ElTiempo. Recuperado de http:/ /www.eltiempo.com/archivo/documento/CMS-3940130

Kress, Gunther \& van Leeuwen Theo. (2001). Multimodal discourse. The modes and media of contemporary communication, Londres, Arnold; Introducción, pp. 1-23.

Traducción: Molina, Laura H., para la cátedra de Producción de Textos de la FBA, UNLP, 2011.

Kossoy, B. (2001). Fotografía e Historia. Buenos Aires: La marca.

Rodríguez M., Tatiana. (2005). Imagen y discurso: Construcción de sentido en las portadas de las revistas Semana y Cambio 1998-2004. Monografía Departamento de Ciencia Política - Facultad de Derecho, Ciencias Políticas y Sociales. Universidad Nacional de Colombia, Bogotá, Colombia.

Salazar. V. (23 de abril de 2015) Ayer y hoy la mirada de un maestro, La Patria.com. Recuperado de http:/ / www.lapatria.com/cultural/ayer-y-hoy-la-mirada-de-un-maestro-189290

Sánchez M., Viviana P. (2006). El ojo fotográfico de Jorge Silva y sus contemporáneos. Trabajo de grado para optar al título de comunicadora social. Facultad de Comunicación y Lenguaje. Pontificia Universidad Javeriana, Bogotá, Colombia.

Serrano, Eduardo. (2006). Historia de la fotografía en Colombia 1950 - 2000. Museo Nacional de Colombia. Bogotá. Editorial Planeta Colombiana. Pág. 24.

Rueda, S y Peña, C. (2012) Nereo López. Un contador de historias. La Silueta.

Rueda, Santiago, "La mala hora. La fotografía campesina en Colombia en los años setenta”, Ensayos. Historia y teoría del arte. Bogotá D. C., Universidad Nacional de Colombia, 2008, No. 15, 12 fotos, pp. 107-127. 